\title{
Cuatro éticas: una mirada desde y más allá de Nietzsche
}

Alejandro Bustamante Fontecha

Universidad Nacional de Colombia 


\title{
Cuatro éticas: una mirada desde y más allá de Nietzsche*
}

Resumen: apoyándose en Nietzsche, cuando es posible, y en otros autores, cuando es necesario, este texto aborda - tomando como base, las tres transformaciones del espíritu enunciadas por Nietzsche al comienzo del Zaratustra, y la noción de voluntad de poder-, la posibilidad de inferir cuatro éticas, desde el punto de vista del poder: una ética de la sumisión orientada hacia la obediencia, una ética de la resistencia orientada hacia la rebeldía, una ética de la supervivencia orientada hacia la dominación, y una ética de la supervivencia orientada hacia el empoderamiento. El propósito de este trabajo es mostrar la inconveniencia de las tres primeras éticas para un adecuado ejercicio de la democracia, y plantear, en cambio, la pertinencia de una ética del empoderamiento.

Palabras clave: ética, supervivencia, dominación, sumisión, resistencia, Nietzsche.

\section{Four ethics: a look from and beyond Nietzsche}

\begin{abstract}
Nietzsche, when possible, and other authors, when necessary, this text addresses - taking as a basis, the three transformations of the spirit enunciated by Nietzsche at the beginning of the Zarathustra, and the notion of the will to power- the possibility of infer four ethics, from the point of view of power: an obedience ethic oriented towards obedience, an ethics of resistance oriented towards rebellion, an ethic of survival oriented towards domination, and an ethics of survival oriented toward empowerment. The purpose of this paper is to expose the inconvenience of the first three ethics for an adequate exercise of democracy, and to propose, instead, the relevance of an ethic of empowerment.
\end{abstract}

Keywords: ethics, survival, domination, submission, resistance, Nietzsche.

Fecha de recepción: 21 de marzo de 2019

Fecha de aceptación: 3 de julio de 2019

Forma de citar (APA): Bustamante-Fontecha, A. (2020). Cuatro éticas: una mirada desde y más allá de Nietzsche. Revista Filosofía UIS, 19(1), DOI: 10.18273/revfil.v19n1-2020008

Forma de citar (Harvard): Bustamante-Fontecha, A. (2020). Cuatro éticas: una mirada desde y más allá de Nietzsche. Revista Filosofía UIS, 19(1), 103-128.

Alejandro Bustamante Fontecha: colombiano. Magíster en Ciencia Política. Profesor de la Universidad Nacional de Colombia.

ORCID iD: orcid.org/0000-0003-4741-2013

Correo electrónico: alejandrobttef@gmail.com, abustama@unal.edu.co

"Artículo de reflexión derivado de investigación. 


\title{
Cuatro éticas: una mirada desde y más allá de Nietzsche
}

\begin{abstract}
El espíritu de los poderes es en el fondo teocrático, y la herejía es a sus ojos peor que cualquier otro pecado. Cualquier tirano quiere imponer la aprobación, y sin embargo, la quiere libre; y al tiempo querría castigar al que se la niegue; no se limita a los actos; quiere ser amado a causa de su poder (Alain, 2016, p. 147).
\end{abstract}

\section{De las tres transformaciones del espirritu a la voluntad de poder}

En un famoso acápite del Zaratustra, en donde expone las fases por las que atraviesa el espíritu en su proceso de autosuperación, menciona Nietzsche que aquel se convierte primero en camello, después en león y, finalmente, en niño. En este relato, el camello representa "el espíritu en que mora la veneración, [...] el espíritu fuerte y resistente", [para el cual] hay muchas cargas pesadas: su fortaleza demanda lo difícil y pesado" (Nietzsche, 2011, p. 35), lo cual le es impuesto por el dragón, quien recibe a su turno el nombre de "Tú debes", y no es otra cosa que la autoridad. El león, en cambio, "quiere apresar la libertad y ser soberano en su propio desierto" (p. 36). Por eso se rebela en contra de "Tú debes" y le replica diciéndole: "Yo quiero". Pero el rebelde león es todavía incapaz de crear valores nuevos, pues solo representa un sagrado no ante el deber expresado en los valores antiguos; "pero crearse la libertad para nuevos actos creadores - de eso sí es capaz el poder del león" (p. 36). Crear valores nuevos, de eso se trata, y esa tarea le corresponde al niño, ya que "el niño es inocencia y olvido, un nuevo comienzo, un juego, una rueda que gira por sí misma, un primer movimiento, un sagrado decir sí" (p. 37).

Al margen de los numerosos análisis que se han hecho de este pasaje, podría afirmarse que Nietzsche está haciendo referencia a tres éticas bien diferentes: i) una ética de la sumisión orientada hacia la obediencia, ii) una ética de la resistencia orientada hacia la rebeldía y, iii) una ética de la libertad orientada hacia la creación. Además, existe una conexión entre las tres transformaciones del espíritu y la voluntad de poder, como queda en evidencia en el siguiente texto, que, prácticamente, se superpone al anterior: 
«Tú debes» — obediencia incondicionada en los estoicos, en las órdenes del cristianismo y de los árabes, en la filosofía de Kant (es indiferente si a un superior o a un concepto). Por encima del «tú debes» está el «yo quiero» (los héroes); por encima del «yo quiero» está el «yo soy» (los dioses griegos) (Nietzsche, 2010b, p. 515).

Si no fuera por las terribles implicaciones que llegó a tener la tercera ética en el desarrollo de la noción de "voluntad de poder" nietzscheana —donde la libertad creadora del niño parece fundirse con la insolente rebeldía del león, tomando partido en favor de los poderosos-, podrían admitirse, sin más, las tres éticas mencionadas. Pero, dada la funesta elección nietzscheana, se hace necesario formular una cuarta ética, leyendo a Nietzsche en clave democrática, para lo cual, habrá qué invertir los términos originales de su pensamiento.

Como se sabe, la voluntad de poder está orientada a exaltar las virtudes de los "animales de rapiña", esos superhombres que actúan como verdaderos depredadores. Aquí debe decirse que fueron los prejuicios políticos del filósofo, alimentados por el darwinismo social prevaleciente en la era imperialista de la época del dominio europeo del mundo (Watson, 2002, pp. 52-65), los que lo llevaron a negar las posibilidades de superación de quienes llamaba "animales de rebaño", y a despreciar las esperanzas alentadas en estas clases por la moral derivada de un humanismo, común al cristianismo, el socialismo y la democracia. Esta moral humanista tendría como propósito proteger a los desvalidos de la desesperación causada por la abyecta condición que les ha sido impuesta, y evitarles acudir a su propia destrucción como única salida. Todo esto se pone en evidencia cuando afirma que:

La moral ha protegido a la vida de la desesperación y del salto a la nada en aquellos hombres y estamentos que han sido violentados y oprimidos por otros hombres: porque es la impotencia frente a los hombres, no la impotencia frente a la naturaleza, la que genera la amargura más desesperada frente a la existencia (Nietzsche, 2008, p. 166).

Aunque es más conocida la posición negativa de Nietzsche hacia el cristianismo, hay que decir que esta posición formaba parte del gran desprecio que sentía el filósofo por todo lo que, desde su punto de vista, se pusiera del lado de los débiles, como se puede ver en este fragmento:

La moral ha tratado a quienes tenían el poder, a quienes ejercían el poder, a los "señores" en general, como los enemigos frente a los cuales el hombre común tiene que ser protegido, es decir, en primer lugar, alentado, fortalecido. La moral, por consiguiente, ha enseñado a odiar y despreciar de la manera más profunda lo que constituye el rasgo de carácter fundamental de los dominadores: su voluntad de poder (Nietzsche, 2008, p. 166). 
Pese a lo chocante que pudiese parecer, debe advertirse que existen muchas pruebas, sobre todo en los Fragmentos póstumos, del desprecio que sentía Nietzsche, no solo por el cristianismo, sino por la democracia, a la cual consideraba responsable de la inaceptación que recibía la voluntad de poder, como se puede constatar cuando dice que: "«la voluntad de poder» es odiada en las épocas democráticas hasta tal punto que la psicología entera de éstas parece orientada a empequeñecerla y a calumniarla" (2008, p. 543). En ese orden de ideas, concibe el auge del movimiento democrático que se está llevando a cabo en Europa, y que identifica con el progreso, como una conjura global del rebaño o como una sublevación de esclavos, lo cual queda dicho de este modo:

[...] creo que el gran movimiento que avanza incontenible, el movimiento democrático de Europa —eso que se llama "progreso" — lo mismo que ya su preparación y precursor moral, el cristianismo- sólo significa en el fondo la enorme e instintiva conjura global del rebaño contra todo lo que es pastor, animal depredador, eremita y César, a favor de la conservación y elevación de todos los débiles, abatidos, malparados, mediocres, medio malogrados, como una prolongada sublevación de esclavos, primero secreta y luego cada vez más asumida, contra toda especie de señores, por último también contra el concepto "señor" [...] (Nietzsche, 2008, p. 82).

Pero Nietzsche se subleva en contra de todos esos sublevados, despreciando a quienes tienen la osadía de despreciar a sus señores; pues con ello, según él, se están oponiendo, sin saberlo, al ascenso de una especie superior de hombre, especie mejor lograda que requiere, para el logro de sus fines superiores, de esclavos sobre los cuales sostenerse. Por esa razón, denuncia la que considera,

una guerra a vida o muerte contra aquella moral que surge del seno y de la conciencia de una especie superior, más fuerte de hombre, de una especie, como se ha dicho, dominadora, — de una especie que, como base y condición, necesita la esclavitud en alguna forma y bajo algún nombre [...] (2008, p. 82).

Obsérvese que por doquier aparece una distinción entre hombres ordinarios y hombres extraordinarios, bajo la contraposición entre hombres excepcionales y hombres comunes, señores y esclavos, especie superior y especie inferior, fuertes y débiles, con la particularidad de que Nietzsche no tiene problema en admitir que esta distinción es obra de una sociedad aristocrática, sociedad que, según él, sería la única que habría emprendido la tarea de elevar al hombre por encima de la abyección en la que estaría cayendo inexorablemente, como consecuencia de la intromisión del igualitarismo. No de otra forma podría entendérselo cuando afirma que "hasta ahora toda elevación del tipo hombre ha sido obra de una sociedad aristocrática que creía en una larga escala de jerarquía y diferencia de valor entre hombre y hombre y que tenía necesidad de la esclavitud" [...] (2008, p. 82). 
En este punto, no hay que llamarse a engaños ni tratar de exculpar a Nietzsche, en nombre de lo que su pensamiento ha representado para el entendimiento del mundo contemporáneo. Sin más, hay que decirlo: todo lo citado anteriormente apunta a lo siguiente: para que el hombre pueda elevarse sobre sí mismo, se tiene que montar sobre sí mismo, lo que en el contexto nietzscheano significa que para que unos hombres se puedan elevar sobre sí mismos —esto es, sacar el mejor provecho de sí mismos- se deben encaramar sobre los hombros de otros hombres. Como se ve, no se trata de una autosuperación inocente: la elevación de unos se hace a costa de la degradación de otros.

De allí que, para que tenga lugar la existencia de los hombres extraordinarios, deberá haber hombres ordinarios que se vean obligados a cargarlos en sus espaldas. Lo terrible es que, si se sigue la lógica argumentativa de Nietzsche, para estos infortunados no hay opción. Y no la hay porque, de acuerdo con esta lógica, ellos constituyen la manifestación viviente de la decadencia o, mejor dicho, ellos son los desechos que va dejando la vida en su proceso de evolución. Decadencia que llevaría inexorablemente a la extinción del hombre, convirtiendo en un imperativo la necesidad de crear una nueva especie, un nuevo tipo de hombre, un hombre superior: el superhombre.

Es que, para Nietzsche, la decadencia forma parte del devenir de la vida: "el fenómeno de la décadence es tan necesario como cualquier ascenso y avance de la vida: eliminarlo no está en nuestras manos" (2008, p. 532). Esta decadencia va asociada a la producción de desechos y a su posterior eliminación, como afirma acá, incluyendo a la humanidad en el proceso: "la décadence es propia de todas las épocas de la humanidad: por todas partes hay materiales de desechos y de ruinas, la eliminación de formaciones de decadencia y de declive es uno de los procesos de la vida misma" (2008, pp. 422ss.).

Por cierto, todo esto suena a darwinismo social. Pero aquí se hace necesario aclarar que Nietzsche no es un darwinista social, en sentido estricto. Y también hay que aclarar que su recepción de Darwin es bastante peculiar, por no decir equivocada en algunos aspectos, como veremos a continuación. Primero que todo, él mismo se presenta como un anti-darwiniano, cuando expresa que:

lo que más me sorprende al revisar los grandes destinos del ser humano es ver siempre ante mis ojos lo contrario de lo que hoy día Darwin y toda su escuela ven o quieren ver: la selección a favor de los más fuertes, de los mejor dotados, el progreso de la especie (2008, p. 561).

Aclaremos que Darwin jamás postuló la selección a favor de los más fuertes, o de los mejor dotados y, mucho menos, el progreso de la especie, como base de su teoría de la evolución. En su interpretación, la evolución, si es que tenía algún sentido, se encaminaba, por lo regular, de lo simple a lo complejo, y hacia la 
aparición de unos organismos cada vez mejor adaptados a su entorno. Y aunque Darwin no lo expresó directamente, hoy en día se acepta la supervivencia de los más aptos —expresión introducida por Spencer, paradójicamente, un darwinista social (Watson, 2002, p. 53)—, como una forma aceptable de caracterizar la evolución, pero no más. Quienes interpretaron la evolución como supervivencia de los más fuertes, de los mejor dotados, y como progreso, fueron, en términos generales, los darwinistas sociales que, además, tenían el prurito de poner a la Europa occidental como modelo. Ahora bien, a partir del mencionado error de interpretación (se trata, realmente, de una falacia), Nietzsche replica que

La selección no se lleva a cabo en favor de las excepciones y de los casos afortunados: los más fuertes y los más felices son débiles cuando tienen en su contra los instintos de rebaño organizados, la pusilanimidad de los débiles, la superioridad numérica (2008, p. 561).

De acuerdo con esto, los más fuertes son también los más felices, pero como son una minoría, terminan siendo apabullados por la superioridad numérica del rebaño organizado, esto es, las mayorías democráticas. Nietzsche no escatima esfuerzos en justificar su ataque en contra de aquellos a quienes considera como productos malogrados de la vida, Ilámense decadentes, desechos, ruinas, mediocres y, en todo caso, entes afectados por la voluntad de nada que, precisamente, es la antípoda de la voluntad de vivir, es decir, la voluntad de poder. Por esa razón arremete contra toda moral que, en su concepto, esté al servicio de aquella voluntad de nada, señalando que,

esta moral dice así: los mediocres tienen más valor que las excepciones, los productos de la decadencia más que los mediocres, la voluntad de nada predomina sobre la voluntad de vida - y la meta de todo ello es por tanto, expresada de manera cristiana, budista, schopenhaueriana: mejor no ser que ser (2008, pp. 561ss.).

\section{La encrucijada nietzscheana y la ética de la dominación}

La primera formulación nietzscheana de esta versión del pesimismo trágico se encuentra en El nacimiento de la tragedia. Allí la pone en labios del sabio Sileno quien, en respuesta a la apremiante insistencia del rey Midas, que lo había hecho atrapar, ex profeso, para preguntarle,

Qué era lo mejor y más deseable para el hombre [le respondió] en medio de una estridente risa: "iMísera estirpe efímera, hijos del azar y de la ardura!, ¿por qué me obligas a decirte algo, lo que te conviene no escuchar? Lo mejor de todo no está en absoluto a tu alcance, a saber, no haber nacido, no ser, ser nada... Y, en su defecto, lo mejor para ti es... morir pronto" (2010a, p. 64). 
En eso consiste la voluntad de nada a la que se refiere Nietzsche. Voluntad que, en su concepto, mueve a las mayorías. Voluntad que, como un imán, atrae la decadencia; que tira hacia abajo. En todo caso, al final de la partida, la culpa de todo la tienen esos impertinentes descamisados sublevados. Esos productos malogrados de la vida, que ponen a la especie en peligro de extinción, si no se los pone oportunamente en su lugar, ya que perjudican el ascenso de los que están llamados a sacar la cara por ella, para evitar su — de otro modo irremediablecaída en los abismos de la nada. Y la culpa de todo la tiene, en primer lugar, —siempre según Nietzsche- el cristianismo, por haberlos protegido, impidiendo poner en práctica su aniquilación, como queda dicho en este pasaje:

La prohibición de la Biblia "ino matarás!" es una ingenuidad en comparación con mi prohibición a los décadents "ino procreéis!" —es peor aún, es una contradicción con respecto a mí... La ley superior de la vida, formulada en primer lugar por Zaratustra, exige que no se tenga compasión con todo desecho y desperdicio de la vida, que se aniquile lo que para la vida ascendente no sería sino obstáculo, veneno, conjura, subterránea hostilidad, —en una palabra, cristianismo... Es inmoral, es contranatura en el más profundo sentido, decir "ino matarás!" (2008, p. 759).

Téngase en cuenta que Nietzsche no está hablando en sentido metafórico; por el contrario, lo está haciendo en un tono bastante grave. La selección de los mejores supone la destrucción de los peores, según entiende. A veces esclavizándolos, a veces exterminándolos, a veces impidiéndoles nacer. Safranski, refiriéndose al respecto, declara que: "sólo se logra crear este «exceso de vida» si a los «demasiados» se les impide la procreación o si, incluso, son eliminados. Para Nietzsche tales pensamientos verdaderamente asesinos proceden del estado dionisiaco" (2001, p. 287). Tan dionisíaco como podría ser una campaña adelantada por cazadores ebrios de sangre, valga decirlo. Que no se trata de una metáfora, queda claro en esta afirmación: "Sólo hay nobleza de nacimiento, sólo nobleza de sangre [...] El espíritu solo, pues, no ennoblece, antes bien, hace falta algo que ennoblezca el espíritu. —¿Qué es lo que hace falta? La sangre" (2010b, p. 874).

Queda claro hacia dónde apunta la filosofía de la voluntad de poder. Se trata de una exhortación a los poderosos para que tengan el coraje de asumir el lugar que les corresponde, en cuya defensa se afirma que "por extraño que suene: se ha de armar siempre a los fuertes contra los débiles; a los felices contra los desgraciados; a los sanos contra los depravados y los lastrados con taras hereditarias" (Nietzsche, 2008, pp. 561ss.). De otro modo: Nietzsche le dio status filosófico al discurso intolerante de la negación del otro, que aquí aparece como el débil, el menesteroso, el insignificante, el malogrado, el parásito, en resumidas cuentas, el desechable, atrapado —según él- por una irresistible voluntad de nada; dando lugar a que nos preguntemos: ¿quién es quién para decidir quién 
vive y quién muere?, ¿quién manda y quién obedece?, ¿qué está bien o qué está mal en este mundo dejado de la mano de Dios? La respuesta queda implícita: es el poder, sin más. Porque — sin caer en un relativismo extremo que nos lleve a decir, con el poeta: "todo, todo me da lo mismo: lo eximio y lo ruin, lo trivial, lo perfecto, lo malo..." (De Greiff, 2013, p. 155), ya que, en este caso, no se trata de valores, sino de personas-, si se adoptase una perspectiva imparcial, resultaría que igual derecho a vivir tendrían el rico y el pobre, el excelso y el malogrado, el brillante y el mediocre, el noble y el villano, el prohombre y el gusano (Serrat); pues no hay, in extremis - para nada ni para nadie, ni ahora ni nunca-, un tribunal supremo de la verdad, un oráculo infalible, una instancia última y definitiva a la que apelar para resolver semejante cuestión. En ese sentido, todo es cuestión de perspectiva, como podría haber señalado el propio Nietzsche. Y de poder, claro está, pues, como queda claro en el conocido discurso de Humpty Dumpty, es el poder quien impone las normas y, por lo tanto, quien establece el significado de las cosas.

No obstante, Nietzsche está dispuesto a ofrecer una justificación. Por eso propone una transvaloración de todos los valores, unas nuevas tablas de la ley, una nueva interpretación del bien y del mal, que recuerda las exhortaciones de Maquiavelo, quien, como se sabe, considera que la política es cuestión de supervivencia, no de moral. De ello da fe el florentino en muchas ocasiones y de diversos modos. Por ejemplo, cuando dice que "está tan lejos el cómo se vive del cómo se debería vivir, que quien renuncie a lo que se hace en aras de lo que se debería hacer, aprende más bien su ruina que su conservación" (Maquiavelo, 2011, p. 51). Para él, la necesidad está por encima del deber. Un príncipe tiene que hacer lo que tiene que hacer. No hay otra opción.

Se trata, por supuesto, del principio de supervivencia del Estado que, a diferencia de Nietzsche, eso sí, constituye para Maquiavelo un fin supremo. Cualquier cosa que ponga en entredicho este principio vital, como el código moral, con su sistema de restricciones (prescripciones, prohibiciones, valoraciones) que intentan regular las acciones, constituye una desventaja, en términos de supervivencia, para quien se somete a ella. Por esas razones, el imperativo de la supervivencia suele chocar con el imperativo moral, con el cual tiene muy pocos puntos de contacto, en cuyo caso, se presenta un desplazamiento del sentido de los valores, por cuanto el criterio técnico prevalece sobre el criterio moral, donde por bueno no se entiende lo virtuoso sino lo eficaz o lo útil, y por malo, lo que no sirve. En ese sentido, la virtud resulta perjudicial y el vicio se percibe como bueno. No otra cosa puede significar esta recomendación de Maquiavelo:

no le preocupe entonces [al príncipe] la fama que da el practicar los vicios sin los que la salvaguardia del Estado es imposible, pues si se considera todo debidamente, se hallará algo que parecerá virtud, pero que al seguirlo 
provocará su ruina, y algo que parecerá vicio, pero que al seguirlo le procura seguridad y bienestar (Maquiavelo, 2011, p. 52).

Valga decir que Nietzsche es mucho más contundente y taxativo, pues subsume la virtud en la voluntad de poder, como se puede apreciar aquí:

El punto de vista natural-egoísta: virtud y poder, idénticos. La virtud no renuncia, desea, no lucha en contra sino a favor de la naturaleza; no es el aniquilamiento sino la satisfacción del afecto más poderoso. Es bueno lo que favorece nuestro poder: malo, lo contrario. La virtud resulta de la aspiración a la autoconservación. "Lo que hacemos lo hacemos para conservar y acrecentar nuestro poder". "Por virtud y poder entiendo lo mismo" (2008, p. 193).

Virtud sin cristianismo, se entiende. Es decir, nihilismo y nuevas tablas de la ley. Esta vez, sin metafísica. Totalmente terrenal. La ley de la selva. En otras palabras, virtud como supervivencia, a secas. Pero no de todos. Nietzsche exige, a voz en cuello, que se le despeje la vía tan solo a los más fuertes, dejando a los débiles tirados a la vera del camino. De allí su desprecio por la democracia, el socialismo y el anarquismo, en una época de tanta agitación social en Europa que impide, según él, percibir el ímpetu decadente que acompaña a tales movimientos, como se puede constatar cuando dice que:

El socialismo - pensado en última instancia como la tiranía de los más vulgares y más estúpidos, de los superficiales, los envidiosos y los comediantes de tres al cuarto- es en realidad el resultado lógico de las ideas modernas y de su latente anarquismo; pero en el aire tibio del bienestar democrático se relaja la facultad de sacar conclusiones o al menos una conclusión (Nietzsche, 2010b, pp. 816ss.).

Cabe observar que, en perfecta armonía con la tradición del pensamiento aristocrático, Nietzsche no hace otra cosa que expresar su protesta contra los efectos perniciosos de la llegada al poder de los mediocres, con su inevitable propagación de la vulgaridad, el mal gusto y la ordinariez. No está de más recordar que ya en su temprano ensayo "Sobre verdad y mentira en sentido extramoral" (2010a, p. 190), Nietzsche consideraba vano todo intento de enaltecer el intelecto humano en cuanto tal, en tanto este solo era el resultado de la consumación del arte del engaño por parte de unos seres débiles en sí mismos, que dependían de este arte como medio para sobrevivir. En ese sentido, no es el intelecto, o su producto más excelso, el conocimiento, lo que conmueve a Nietzsche. El enigma se resuelve en la posterior evolución de su pensamiento, con la formulación de la noción de voluntad de poder.

La voluntad de poder es presentada por Nietzsche como un principio despersonalizado que afecta a todo el orden viviente y lo desborda, alcanzando 
el campo de las reacciones químicas y físicas, en fin, las dinámicas que rigen el movimiento del universo entero en medio de un enorme juego de suma cero (2010b, p. 831). En un primer momento, aparece como un escenario en donde lo fuerte subsume lo débil: "La apropiación e incorporación es sobre todo un querer subyugar, un formar, configurar y reconfigurar hasta que finalmente lo sometido ha pasado totalmente al poder del atacante y lo ha acrecentado" (2008, p. 282). Después se define como una fuerza configuradora y expansiva:

[...] todo centro de fuerza - y no solamente el ser humano- construye el mundo entero restante a partir de sí mismo, es decir, lo mide, lo manipula, lo configura según su fuerza [...] De acuerdo con mi representación, cada cuerpo específico aspira a dominar el espacio entero y a extender su fuerza (-su voluntad de poder) y a repeler todo lo que se opone a su expansión. Pero tropieza constantemente con aspiraciones iguales de otros cuerpos y acaba arreglándose ("uniéndose") con aquellos que le son bastante afines: -así conspiran entonces juntos para lograr el poder. Y el proceso continúa... (2008, p. 603).

Para agregar más adelante que también es acumulación de fuerzas, crecer a costa de otro:

La voluntad de acumular fuerza como específico para el fenómeno de la vida, para la nutrición, la reproducción, la herencia, para la sociedad, el Estado, las costumbres, la autoridad ino deberíamos tener el derecho de admitir esta voluntad como causa motora incluso en la química? iY en el orden cósmico? No meramente constancia de la energía: sino economía maximal del consumo: de manera que el querer-llegar-a-ser-más-fuerte por parte de todo centro de fuerza es la única realidad, — no autoconservación, sino apropiación, querer-llegar-a-dominar, querer-llegar-a-ser-más, quererllegar-a-ser-más-fuerte [...] La vida como la forma del ser que nosotros mejor conocemos es específicamente una voluntad de acumulación de fuerza: todos los procesos de la vida tienen aquí su punto de apoyo: nada quiere conservarse, todo debe ser sumado y acumulado (2008, p. 535).

De este modo, configuración, expansión, crecimiento y acumulación de fuerzas, a las que habría que agregar, elevación por encima de sí mismo, definen la voluntad de poder. Pero en medio de ese inmenso marco, lo que específicamente conmueve a Nietzsche es la grandeza del crear, inherente a la supervivencia de la vida, que se eleva — de acuerdo con la perspectiva del darwinismo social, no de Darwin quien, como ya se dijo, jamás entendió la evolución como superación o elevación de unas especies u organismos por encima de sí mismos o de otrosmientras arrastra tras de sí lo parasitario — lo decadente, la plebe-, que siempre trata de adherírsele para aprovecharse de ella, sobre todo, cuando se encuentra frente a las especies más elevadas, como queda dicho en el ítem 19 del capítulo "De viejas y nuevas tablas" del Zaratustra: 
[...] - yo construyo una cordillera compuesta de montañas cada vez más sagradas-

Mas, adondequiera que subáis conmigo ioh hermanos míos, tened cuidado de que no suba con vosotros un parásito!

Parásito: es un bicho rastrero y escurridizo que quiere engordar de vuestros rincones heridos y enfermos.

Y su arte consiste en adivinar en las almas ascendentes dónde están cansadas: en vuestra aflicción y disgusto, en vuestro delicado pudor hace su repugnante nido.

Donde el fuerte es débil, y donde el noble es demasiado condescendiente, -ahí construye su repugnante nido: el parásito vive donde el grande tiene pequeñas heridas ocultas.

¿Cuál es la especie más elevada de todo lo existente y la más baja? El parásito es la más baja; pero quien pertenece a la más elevada, alimenta a la mayor parte de los parásitos.

El alma, en efecto, que tiene la escala más larga y es la que puede descender más; ¿cómo no deberían asentarse en ella la mayoría de los parásitos?(2010a, p. 250).

En ese sentido, el parasitismo del plebeyo constituye, según Nietzsche, la fuente del mal. Vive a costa de la exuberancia del virtuoso, del mejor dotado, del que se eleva sobre sí mismo. Por eso afirma: "El mal es: abusar de las virtudes de otros seres que son de naturaleza superior (parasitismo)" (2010b, p. 329). Y para enfrentar este mal, propone una solución radical: "ia lo que cae, habría, además, que darle un empujón!" (2010a, 251). Toda ayuda humanitaria, gesto compasivo o acto solidario hacia el desvalido, queda pues descartado. Esto es comprensible si se tiene en cuenta que su visión no comulga con el antropocentrismo ni, mucho menos, con el humanismo, sino que se encuentra cimentada en una especie de biocentrismo de trasfondo estético (de allí el episodio del caballo de Turín), donde una cosa queda clara: Nietzsche exalta al depredador — a quien identifica con el creador, el poderoso y el superviviente-, en quien pone todas sus esperanzas, y desprecia al parásito - a quien identifica con el desvalido, el malogrado y el decadente- por cuanto, a su parecer, constituye un lastre para el ascenso de la vida.

De todo lo anterior, puede inferirse que la tercera ética, en la versión nietzscheana de la voluntad de poder, sirve a los intereses de las élites políticas y económicas de las sociedades imperialistas que estaban en pleno auge en tiempos de Nietzsche, las cuales, como señalan Villares y Bahamonde (2001), prosperan mediante la imposición de determinadas formas de intercambio desigual sobre sus colonias. Sin embargo, esta ética juega un papel análogo en sociedades dominadas por la predatocracia, como la colombiana. Ahora bien, lo que, desde una perspectiva colonial, imperialista y predatoria -aristocrática u oligárquica, da lo mismo—-, se percibe como una solución, desde una perspectiva democrática debe interpretarse como un problema. Una ética de la dominación no es compatible, de ninguna manera, con la democracia y Nietzsche lo sabía 
muy bien. Y donde quiera que se ponga en práctica, se tratará de una ética de la supervivencia que deviene en una exaltación del depredador. Por donde se la mire, una verdadera amenaza para la humanidad y la vida, pero ahí está.

\title{
3. Ética de la sumisión
}

A su turno, la ética de la sumisión (primera ética), no es aceptable por cuanto se fundamenta en una exaltación autocomplaciente de la obediencia. Debe advertirse que esta ética ha sido promovida desde tiempos inmemoriales por todo tipo de religiones (monoteístas y politeístas), pero Nietzsche, como acabamos de ver, solo abordó la crítica del cristianismo, y lo hizo para contraponerlo con la voluntad de poder, en una perspectiva muy diferente de la que seguiremos ahora. Una formulación explícita de la ética de la sumisión aparece, con una pizca de intimidación, ya en el apóstol Pablo, en su Carta a los romanos, donde dice:

\begin{abstract}
${ }^{1}$ Sométase toda persona a las autoridades superiores; porque no hay autoridad sino de parte de Dios, y las que hay, por Dios han sido establecidas. ${ }^{2}$ De modo que quien se opone a la autoridad, a lo establecido por Dios resiste; y los que resisten, acarrean condenación para sí mismos. ${ }^{3}$ Porque los magistrados no están para infundir temor al que hace el bien, sino al malo. ¿Quieres, pues, no temer la autoridad? Haz lo bueno, y tendrás alabanza de ella; porque es servidor de Dios para tu bien. ${ }^{4}$ Pero si haces lo malo, teme; porque no en vano lleva la espada, pues es servidor de Dios, vengador para castigar al que hace lo malo. ${ }^{5}$ Por lo cual es necesario estarle sujetos, no solamente por razón del castigo, sino también por causa de la conciencia. ${ }^{6}$ Pues por esto pagáis también los tributos, porque son servidores de Dios que atienden continuamente a esto mismo. ${ }^{7}$ Pagad a todos lo que debéis: al que tributo, tributo; al que impuesto, impuesto; al que respeto, respeto; al que honra, honra (Romanos 13, 1-7).
\end{abstract}

También se puede hallar un propósito semejante y con un tono parecido, incluso más tempranamente, en un texto del Eclesiastés donde se presenta la obediencia como sabiduría:

${ }^{2} \mathrm{Te}$ aconsejo que guardes el mandamiento del rey y la palabra del juramento de Dios. ${ }^{3}$ No te apresures a irte de su presencia, ni en cosa mala persistas; porque él hará todo lo que quiere. ${ }^{4}$ Pues la palabra del rey es con potestad, ¿y quién le dirá: ¿Qué haces? ${ }^{5} \mathrm{El}$ que guarda el mandamiento no experimentará mal; y el corazón del sabio discierne el tiempo y el juicio (Eclesiastés 8, 2-5).

No obstante, la versión más extrema de esta ética se encuentra en el islam, que precisamente significa: sumisión. Por cierto, en el Corán se encuentra un ejemplo muy claro en este pasaje: 
59. iOh, creyentes! Obedezcan a Dios, obedezcan al Mensajero y a aquellos de ustedes que tengan autoridad y conocimiento. Si realmente creen en Dios y en el Día del Juicio, cuando tengan discrepancias remítanlas al juicio de Dios y del Mensajero, porque en ello hay bien y es el camino correcto (Corán, IV, La mujer).

De acuerdo con un comentarista,

este versículo establece que la obediencia a Dios y a Su Mensajero es absoluta, pero que la obediencia a las personas de autoridad y conocimiento es relativa, y es debida siempre que no contradiga los principios establecidos en el Corán y la Sunnah (Corán, IV, La mujer).

En ese sentido, se deja claro que las autoridades terrenales, aunque sean merecedoras de obediencia, siempre estarán por debajo de la palabra consignada en los textos sagrados. Obviamente, esto quedará supeditado a cuestiones de interpretación. La ética de sumisión también ha sido promovida por los monarcas, a lo largo y ancho de la historia occidental, quienes tuvieron a bien mantener el binomio Dios y Rey mientras pudieron, como garantía para obtener la obediencia de sus súbditos. Resulta obvio que esta ética se fundamenta en el principio de autoridad, la cual procede — según se dice- de Dios, quien, para el caso, se desempeña como la fuente suprema de esta. De Él pasa a sus representantes en la tierra, quienes gobiernan en su nombre; razón por la cual, es a Él y solo a Él a quien deben rendir cuentas. Pero no se precisa cuándo ni cómo. Mientras tanto, para los súbditos queda el despliegue de pompa y circunstancia destinado a deslumbrarlos, mientras se destaca paralelamente la superioridad de las élites dominantes, como pone de presente Ferrero en este pasaje:

Desde tiempos inmemoriales la legitimidad monárquica ha venido descansando en la alianza de oro con el hierro, en el matrimonio entre la fuerza y la riqueza. La dinastía reinante no solo debía poseer la mayor fortuna del país, excepción hecha, claro está, de la Iglesia, sino que además tenía que ser considerablemente más rica que las más ricas familias, derrochar con una prodigalidad insaciable en las más diversas y contradictorias tareas o encomiendas: guerras, armamento, obras públicas, beneficencia y prebendas de todas clases, lujo público, lujo de la Corte, de los familiares, gigantescos palacios y castillos de mil habitaciones, fiestas y paradas de características fabulosas (1991, p. 151).

Ferrero lo ha puesto en los términos precisos: alianza de oro con el hierro, matrimonio entre la fuerza y la riqueza; sobre estos pilares se asienta la legitimidad monárquica desde tiempos inmemoriales. En verdad, de eso se trata, pero sus beneficiarios y sus agentes no parecen muy dispuestos a aceptar una presentación tan escueta. Eso explica la destemplada y, en ocasiones, exacerbada recepción de que fue objeto El príncipe de Maquiavelo en los círculos del poder monárquico 
europeo, con posterioridad a la publicación de la obra (1532). Uno de los ejemplos más conspicuos lo constituye el libro, Antimaquiavelo o Refutación del Príncipe de Maquiavelo, escrito por Federico II de Prusia y publicado anónimamente en La Haya, bajo el auspicio y edición de Voltaire, en 1740. Pero un examen cuidadoso del contenido de este texto y de las circunstancias en que se escribió, contrastándolo con el texto del diplomático florentino, mostrará que lo que aparenta ser una interpretación antagónica sobre la política, o sobre el papel y la responsabilidad del gobernante, no es otra cosa que el abordaje de dos objetos diferentes: en Maquiavelo, del poder fáctico y, en Federico II, del poder válido.

Es importante aclarar que Federico de Prusia escribió este libro cuando todavía era príncipe y se podía dar el lujo de pensar con el deseo; incluso hasta puede suponerse que, quizás, lo haya hecho de buena fe. Sin embargo, tan pronto ocupó el puesto de su padre, como rey de Prusia, sus acciones desmintieron todo lo que había dicho y prometido antes, lo cual llevó a un Voltaire desengañado, a decir, en el prefacio del libro, que "Pronto se vio [...] que Federico II, rey de Prusia, no era tan enemigo de Maquiavelo como el príncipe heredero había parecido serlo" (Federico II de Prusia, 1995, p. XLVIII). De hecho, el filósofo francés va todavía más lejos, señalando que un libro como El Antimaquiavelo, salido de la pluma de un príncipe, habría sido una jugada maestra de maquiavelismo que no habría incomodado para nada al propio Maquiavelo. Aunque no le parece que Federico de Prusia fuera capaz de tantos alcances, como deja claro en su comentario:

Al rey de Prusia, algún tiempo antes de morir su padre, se le ocurrió escribir contra los principios de Maquiavelo. Si Maquiavelo hubiera tenido un príncipe por discípulo, la primera cosa que le hubiera recomendado habría sido escribir contra él. Pero el príncipe heredero no hubiera comprendido tanta sutileza (Federico II de Prusia, 1995, p. XLVIII).

Entrando en materia, diríase que casi desde un comienzo saltan a la vista dos grandes preocupaciones de Federico de Prusia, preocupaciones que, de paso, podrían constituir el paradigma de todo gobernante que aspire a la legitimidad: i) cuidar su buena imagen y ii) no dar mal ejemplo. Esto nos recuerda la famosa sentencia atribuida a Julio César: la esposa del César no solo debe ser honesta, sino parecerlo; pero, como se verá a continuación, tal honestidad no parece estar fundamentada en motivos desinteresados, propiamente dichos, sino todo lo contrario. La primera preocupación hace referencia al cuidado de la reputación de los gobernantes, quienes deben proteger su imagen ante el ineludible escrutinio de la opinión pública, para evitar que sus malas acciones los lleven a ser detestados por sus súbditos, como queda expresado en este pasaje:

[...] los príncipes no sabrían ocasionar mal alguno impunemente, ya que, aun cuando sus súbditos no les castiguen ni tampoco queden fulminados por rayos celestiales, deben temer a la opinión pública; será su reputación la 
que quede hecha trizas y su castigo consistirá en ver citado su nombre entre los monstruos que repugnan a la humanidad, además de verse detestado por sus súbditos (Federico II de Prusia, 1995, p. 24).

Más adelante es mucho más específico, detallando las razones para ser cuidadosos con su comportamiento y describiendo los riesgos a que se expone su imagen, debido a la posición que ocupan, como se puede ver aquí:

Se sabe muy bien hasta qué punto es curioso el público; es un animal que lo ve todo, que lo oye todo, y que divulga cuanto ha visto y oído. Si la curiosidad de este público examina la conducta de los particulares, es para entretener su ociosidad; pero cuando juzga el carácter de los príncipes, lo hace siguiendo su propio interés. También los príncipes se hallan expuestos, y más que el resto de los hombres, a los juicios y razonamientos de la gente; son como astros hacia los que un pueblo de astrónomos hubiese dirigido sus telescopios y astrolabios; los cortesanos que les observan [...] hacen cada día sus observaciones; un gesto, un guiño, una mirada les traiciona; y los pueblos se familiarizan con ellos a base de conjeturas; en una palabra, en tan escasa medida como el sol puede cubrir sus manchas, $[. .$.$] poco pueden$ hacer los grandes príncipes por ocultar sus vicios y el fondo de su carácter a los ojos de tantos observadores (Federico II de Prusia, 1995, p. 121).

La lección es clara: por más que lo intenten, los gobernantes no podrán evitar que sus acciones sean observadas, y como tampoco pueden evitar ser descubiertos, es mejor no tratar de aparentar lo que no son. En otras palabras, deben suprimir sus vicios a la vez que alimentan sus virtudes. No sea que los vayan a sorprender... Esto se puede apreciar claramente en este juicio:

El valor es bueno; pero, ipor qué los príncipes deben contentarse con aparentar estas virtudes?, ¿por qué no las deben poseer de hecho? Si los príncipes no poseen estas cualidades efectivamente, harán muy mal en aparentarlas, notándose mucho que el actor y el héroe representado son dos personajes bien distintos (Federico II de Prusia, 1995, p. 130).

Esto en relación con el cuidado de la imagen. En cuanto a la conveniencia de no servir de modelo de mal comportamiento, el príncipe Federico de Prusia se apresura a prevenir al gobernante para que no sea víctima de su propio invento. $Y$ en esto no le falta razón, pues existen múltiples evidencias de que la divulgación de las enseñanzas de Maquiavelo se ha convertido en el manual, no solo de los políticos, los revolucionarios y los conspiradores de cualquier pelambre, sino de los empresarios, y hasta sirven de base en casi todos los programas de entrenamiento en coaching. De allí la pertinencia de la advertencia de Federico de Prusia, cuando dice que:

Abusar de la buena fe de los hombres, [...] utilizar ardides infames, traicionar, perjurar, asesinar: esto es lo que el doctor en perversidad llama 
"prudencia". [...] Me pregunto si el mostrar cómo se puede faltar a la palabra dada y cómo jurar en falso tiene algo que ver con la prudencia. Si vos socaváis la buena fe y el juramento, ¿̇cuáles serán las garantías de que dispondréis sobre la fidelidad de los hombres? [...] Al dar vos ejemplos de traición, siempre habrá traidores que os imitarán (Federico II de Prusia, 1995, pp. 51ss.).

Además, los modelos históricos en los que se apoya Maquiavelo (con frecuencia, criminales ambiciosos e inescrupulosos) no son, ni mucho menos, modelos a seguir para ninguna persona que aspire a ser considerada honesta. Pero no se debe olvidar que el florentino escribió un tratado para una situación de excepción y no para una de normalidad. Sin olvidar que este tratado no estaba dirigido al público en general (vulgo), sino a los príncipes; pero como no se puede evitar que estas recomendaciones caigan en las manos menos indicadas — digamos que en un menor de edad-, tampoco le falta razón a Federico de Prusia cuando advierte que,

En el caso de un hombre cuyo instinto se halle inclinado hacia la maldad, las biografías de un Agatocles o de un Oliverotto de Fermo son capaces de cultivar ese peligroso germen al que presta cobijo dentro de su fuero interno sin tan siquiera saberlo (Federico II de Prusia, 1995, p. 58).

Por último, Federico de Prusia se expresa como sería de esperar que lo hiciese cualquier mandatario - aristocrático o democrático, no importa-, que es como de hecho lo suelen hacer. Justo a esto, es a lo que se le llama lenguaje políticamente correcto:

Compárese al príncipe de Fenelón con el de Maquiavelo. En el primero se observará el carácter de un hombre honesto, donde se dan cita la bondad, la justicia, la equidad y, en una palabra, todas las virtudes elevadas a un grado eminente; se diría que nos encontramos ante una de esas inteligencias puras programadas por la naturaleza para velar por el gobierno del mundo. En el segundo nos toparemos con la perversidad, el engaño, la perfidia, la traición y todos los crímenes imaginables; se trata, en definitiva, de un monstruo que ni siquiera el infierno acertaría bien a engendrar. Mientras que, al leer el Telémaco de Fenelón, se diría que nuestra naturaleza se asemeja a la de los ángeles, cuando uno lee el Príncipe de Maquiavelo, parece aproximarse más a la de los demonios del infierno (Federico II de Prusia, 1995, pp. 48ss.).

Aquí se pone en evidencia lo que podríamos llamar el doble vínculo agenciado por los gobernantes: mientras, por un lado, secretamente están persuadidos, con Maquiavelo, de que la naturaleza del hombre se aproxima más a la de los demonios, por otro, en público, se esfuerzan en hacer creer que esa naturaleza se asemeja más a la de los ángeles, y que bastaría con proporcionarles una educación adecuada para hacerla emerger. 
Pero, ya se trate de ángeles o de demonios, el propósito de todo gobernante es conseguir la obediencia a la autoridad por parte de los gobernados. Como si la obediencia fuera un bien en sí mismo, sin tener en cuenta los peligros que acarrea cuando se realiza "sin resistencia ni crítica" —para utilizar una expresión weberiana-, caracterizando aquella "ausencia de pensamiento" que Arendt asocia con la banalidad del mal (2002, pp. 31ss.). El problema identificado por Arendt - recordémoslo- se presenta ante un hombre ordinario — para el caso, Adolf Eichmann - que ha cometido actos realmente monstruosos sin que se le pueda acusar por ello de ser un monstruo y que, por si fuera poco, exhibe la buena conciencia de la gente auténticamente malvada y no la mala conciencia de la gente buena. En otras palabras, se trata de la condición de un hombre común, que actúa como un monstruo, sin llegar a serlo, por cuanto no lo hace siguiendo el impulso de motivaciones perversas (odio, venganza, sadismo), sino bajo la convicción de que está procediendo bien, al limitarse a cumplir a cabalidad las órdenes recibidas de sus mandos superiores, sin importar la naturaleza de estas y sin cuestionarse si acaso no estará causando un mal porque, para ello, tendría que haber utilizado su facultad de pensar, que seguramente le habría permitido distinguir si lo que hacía estaba bien o estaba mal, independientemente de lo que dijeran los demás. Vale la pena mencionar que la tesis de la banalidad del mal fue demostrada empíricamente por Milgram y Zimbardo, en estudios diferentes, y estos resultados fueron analizados por Bauman en su ética de la obediencia (2011, pp. 180-198).

Hasta ahora hemos mostrado cómo la ética de la sumisión ha sido patrocinada, bien por las religiones, o bien por las monarquías. A continuación, mostraremos cómo - aunque resulte paradójico— la ética de la sumisión también es promovida por los gobernantes de los Estados democráticos, mediante sus rituales patrióticos de legitimación y sus bienintencionados procesos de formación ciudadana, más interesados en que la gente se porte bien —que obedezca- que en desarrollar competencias ciudadanas para gestionar adecuadamente las campañas de defensa y lucha por sus derechos, en las ocasiones en que estas se lleven a cabo. A propósito, ese es el lema de la campaña promovida por la Alcaldía de Medellín, bajo la administración de Federico Gutiérrez, sobre la cual puede leerse, en la página oficial de la Alcaldía de Medellín, lo siguiente:

Medellín somos todos. iPortate bien! Es la campaña con la que la Alcaldía de Medellín invita a erradicar los principales comportamientos que alteran la convivencia ciudadana como son las riñas, el ruido y la mala disposición de las basuras. "Medellín somos todos. Portate bien", busca crear conciencia sobre los comportamientos que más alteran la convivencia ciudadana y promueve la corresponsabilidad ciudadana como solución a los conflictos y hace visibles las medidas correctivas que establece el nuevo Código de Policía y Convivencia. Esta campaña es liderada por las secretarias de Cultura Ciudadana, Seguridad y Comunicaciones, y cuenta con el apoyo de la Policía Metropolitana del Valle de Aburrá, el Ejército Nacional y 
la Secretaría de Movilidad. ¿Por qué necesitamos trabajar en una mejor convivencia? Para no perder más vidas:

- En el 2016 hubo 96 homicidios por convivencia, los cuales corresponden al $18 \%$ de los homicidios sucedidos en la ciudad.

- El 33\% de los homicidios por convivencia ocurrido (sic) en el 2016 se dieron en la comuna 10.

- En el 2017 han sucedido 16 homicidios por convivencia, 3 de ellos en la comuna 10" (Alcaldía de Medellín, Campaña Portate Bien).

Obsérvese que bajo el concepto de "homicidios por convivencia" se atribuye, sin más, la responsabilidad de una parte importante de los homicidios ocurridos en la ciudad, a los ciudadanos comunes y corrientes, sin averiguar de qué tipo de personas se trata, a qué se dedican, si tienen antecedentes penales, y las razones de la agresión. De este modo, se responsabiliza a todos los habitantes de la ciudad, de los delitos cometidos por unos cuantos, encubriendo a los verdaderos responsables (que pueden ser las organizaciones criminales o la delincuencia común, en ejercicio de sus acciones, o sus miembros, actuando por cuenta propia para resolver conflictos privados, o tratarse de riñas callejeras donde, por lo menos, uno de los contrincantes ejerce actividades criminales y está habituado a usar armas, o involucrar a exmilitares o expolicías corruptos, para solo mencionar algunas posibilidades).

Esto no es más que una falacia que, disimuladamente, busca mantener el establishment. Pues si existe algún espacio para el despliegue de estratagemas y de triquiñuelas, ese espacio es, sin duda, el de los procesos de legitimación democrática. Y esto ocurre así, porque estos procesos se llevan a cabo, por lo regular, en el espacio público, espacio que suele ser tratado como tierra de nadie y donde los más audaces y taimados saben sacar el mayor provecho de las oportunidades, mientras sus astutas jugadas pasan desapercibidas ante la mirada desprevenida de los incautos transeúntes —los ciudadanos de a pie-, y nos topamos de nuevo con el asunto aquel de los hombres ordinarios, de esos a los que solo les alcanzó para ser invitados al baile de los que sobran (Los prisioneros). Por agenciar una ética del lacayo, esta perspectiva también se debe descartar.

\section{4. Ética de la resistencia}

Esta ética posee un indiscutible carácter heroico que la hace tremendamente seductora, pero también temible, ya que suele alimentar la desmesura que acompaña las tentaciones totalitarias del rebelde —ese desobediente empedernido condenado por todas las religiones y por todos los gobiernos, sean estos monárquicos o democráticos-, quien, por estar habituado a arriesgar su 
vida, a forzar el curso de los acontecimientos y a sentirse un ser extraordinario, puede llegar a convencerse de que tiene derecho a imponerse sobre los demás y a controlar sus vidas. Detengámonos en el carácter heroico de la ética de la resistencia, aclarando de antemano que Nietzsche desprecia el "culto a los héroes" promovido por Carlyle y rechaza cualquier conexión con este autor (1976, p. 57), por lo cual, seguiremos otro rumbo.

En principio, cabe destacar el estrecho vínculo que existe entre resistencia, rebeldía y heroísmo. Esto se debe a que, por su condición, la resistencia se ejerce contra un poder desproporcionadamente superior que tratará de imponerse a como dé lugar. Es inminente el riesgo de ser aplastado por él pero si, no obstante, la resistencia persiste, se han de buscar otras salidas para evitar ser aniquilado, lo cual conduce forzosamente a una situación de rebeldía. En este caso, lo primero que se pone en evidencia es la enorme diferencia entre los dos órdenes de magnitud enfrentados y la sensación que eso produce, que como veremos, según Kant define la sensación de lo sublime.

El filósofo de Königsberg abordó este problema de dos maneras: oponiendo lo finito a lo infinito, y lo muy pequeño a lo inmensamente grande. Así encuentra que lo finito, por enorme e inconmensurable que pueda llegar a ser, siempre resulta insignificante ante lo infinito, dice Kant: "lo infinito, empero es absolutamente (no sólo comparativamente) grande. Comparado con él, todo lo otro (magnitudes de la misma especie) es pequeño" (1977, p. 156). Dos siglos antes, el matemático y filósofo Blaise Pascal, plasmaba, con afectada perplejidad, en sus Pensamientos, el asombro y terror que le inspiraba la eternidad del tiempo y la infinitud del espacio ante a la impotente volatilidad de su existencia (1984, pp. 56ss.), que condensó en su célebre confesión: "El silencio eternal de estos espacios infinitos me aterra" (p. 57). La infinitud siempre ocasiona esa sensación de agradable terror que acompaña, según Kant, el sentimiento de lo sublime: "sublime es aquello en comparación con lo cual otra cosa es pequeña" (1977, p. 151). Pero Kant no se refiere solo a la sensación que causa la insondable desproporción entre lo infinito y lo finito, sino a la que produce el contraste entre la irresistible inmensidad de la naturaleza y la "insignificante pequeñez" del poder humano:

Rocas audazmente colgadas y, por decirlo así, amenazadoras, nubes de tormenta que se amontonan en el cielo y se adelantan con rayos y con truenos, volcanes en todo su poder devastador, huracanes que van dejando tras sí la desolación, el océano sin límites rugiendo de ira, una cascada profunda en un río poderoso, etc. [...], reducen nuestra facultad de resistir a una insignificante pequeñez, comparada con su fuerza (1977, p. 163).

Ahora bien, como observa Teresa Santiago, 
es curioso que esta visión del poder ingente de la naturaleza y, por ende, la revelación de nuestra pequeñez, sea uno de los temas favoritos de los románticos que vendrán asociados al Sturm und Drang [tormenta e ímpetu] ${ }^{1}$ y no a la filosofía racionalista ilustrada de Kant (2009, p. 29).

Es pues, el romanticismo, no el racionalismo, el que alienta el culto del héroe, ese personaje indómito de quien se admira esa sublime actitud de desafío ante el peligro y quien, sobreponiéndose a sus propias limitaciones, aborda una empresa cuya magnitud excede, con mucho, sus precarias fuerzas, llegando incluso a dar la vida por una causa que se sabe perdida de antemano (v.gr. el Che Guevara). Hay en lo heroico un espíritu prometeico: la rebeldía frente a los condicionamientos externos y la voluntad de sobreponerse a las propias limitaciones, pagando por ello las consecuencias del caso. Pero la rebeldía, pese a la fascinación que puede provocar, no crea nada, como dice Nietzsche. Es solo promesa; a lo sumo, un paso necesario mas no suficiente para alcanzar la plenitud del ser, y suele extraviarse en el intento.

Cabe aclarar que existen dos versiones de la ética de la resistencia: una violenta y otra no-violenta. La primera está orientada hacia la toma del poder y ha sido la vía predilecta de los movimientos revolucionarios de inspiración marxista. Si se conquista este objetivo, tras la toma del poder aparece una nueva élite que, en muchos aspectos, repite las mismas prácticas abusivas de las élites derrocadas, en cuyo caso, concluye irremediablemente convertida en lo mismo que había combatido y despreciado. Infortunadamente, en muchas ocasiones, los combatientes rebeldes ni siquiera se resignan a esperar la toma del poder para tiranizar a las masas populares que dicen defender o en cuyo nombre se han levantado en armas. El efecto de acostumbramiento que acompaña sus acciones al margen de la ley, suele llevarlos a naturalizar su comportamiento violento y despótico, hasta el punto de perder la capacidad de dimensionar la gravedad del impacto trágico y criminal de sus atentados contra la población civil, como se puede constatar en muchos de los ataques perpetrados por las organizaciones guerrilleras colombianas en las últimas décadas.

Por otra parte, si no se sigue la vía armada, la práctica de una ética de la resistencia tendría que conformarse con la realización esporádica de algunos trabajos de denuncia, o limitarse a servir de fundamento a las movilizaciones ocasionales que se realicen como mecanismo para ejercer presión sobre determinados temas, muy puntuales. La participación y el impacto dependerían del entusiasmo generado entre los seguidores, y se agotarían prontamente tras la realización de algunas salidas o la cosecha de algunos triunfos, con lo cual, de

\footnotetext{
${ }^{1}$ Movimiento estético que apareció en el último tercio del siglo XVIII, preludio del romanticismo, del cual participaron Goethe y Schiller.
} 
cierta forma, el movimiento se vería convertido en flor de un día. Sus alcances, entonces, serían muy modestos. Ciertamente necesarios, pero no suficientes. Así pues, por el lado que se le mire, la ética de la resistencia no parece ser una opción satisfactoria.

\section{5. Ética del empoderamiento}

Después de haber examinado las características y los inconvenientes de la ética de la dominación (tercera ética), la ética de la sumisión (primera ética), y la ética de la resistencia (segunda ética), ha llegado el momento de abordar la ética del empoderamiento; ética cuyo principio rector está inspirado en dos propósitos: primero, elevar al desvalido por encima del estado de postración en que se encuentra - pues carece de fuerzas suficientes para levantarse por sí mismo- $-y$, segundo, alentar en todo aquel que se encuentre en condición de hacerlo, a elevarse por encima de sí mismo, poniendo en práctica lo que Safranski —refiriéndose a Nietzsche-denomina efecto Münchhausen² (2001, p. 300).

Ante todo, se han de utilizar los recursos disponibles —incluyendo el apoyo de posibles aliados estratégicos procedentes de las clases medias y altas de la sociedad- para asignar un lugar al subalterno en el difícil campo de batalla dominado por los poderosos. En ese caso, el subalterno deberá encontrar el modo de acceder a sus secretos, en especial, los que son conocidos como trucos del negocio, para lo cual podrá valerse de aquellos asesores y tutores que no se hayan envilecido con el poder. En el proceso, deberá tomar conciencia de sus propias capacidades, potencialidades, alcances y limitaciones; porque no todos aquellos que lo intentan pueden conquistar las mismas metas. En esto hay que ser realistas: algunas cosas no están al alcance de todos, porque no todos tienen la madera necesaria para conseguirlas.

Conviene advertir que abordar el campo de batalla de los poderosos es como adentrarse en la espesura de la jungla. Allí se encontrarán depredadores y parásitos por doquier, y existirá una alta probabilidad de ser destruido o saqueado por ellos, en la primera salida en falso. Nadie ha dicho que esto sea cosa fácil, pues no se llega a ser poderoso por la gracia de Dios. Antes bien, el poderoso es un competidor de alto rendimiento que ha perfeccionado competencias especiales para mantener su posición privilegiada. Ciertamente, a él tampoco le resultan fáciles las cosas. Para enfrentar las dificultades, los riesgos y los imprevistos, se ha preparado, sometiéndose a un duro entrenamiento, soportando fuertes presiones y superando arduas pruebas.

\footnotetext{
${ }^{2}$ Expresión inspirada en la historia Las aventuras del Barón Münchhausen, donde este personaje relata que, en una ocasión, encontrándose al borde de una muerte segura, montando su caballo mientras ambos se hundían en un pantano, se salvó a sí mismo y a su jamelgo, apretando sus piernas y jalando su coleta hacia arriba con todas sus fuerzas.
} 
En síntesis, ha sobrevivido a un exigente ritual de iniciación que puede haberlo transfigurado. Quizás hasta se haya deshumanizado un tanto en el proceso, perdiendo la empatía y apartando la compasión de su ser. Por lo regular, conoce sus alcances y sus límites y actúa en consecuencia, sin contemplaciones de ninguna clase. En eso radica la razón de su éxito. El poderoso siempre hace lo que tiene que hacer y sigue su camino. Si cae, se vuelve a levantar. Si encuentra obstáculos, los derriba, los rodea o salta por encima de ellos. Si necesita ayuda, la consigue. Siempre es capaz de llegar más lejos que los demás. Siempre los supera, de algún modo. De eso y para eso vive.

Pese a todo, no hay por qué satanizar al poderoso. Si su consigna es llegar tan lejos como pueda y lo ha conseguido, también es porque los demás se lo han permitido. Si ha podido escalar tan alto, es porque otros le han ayudado a trepar hasta esas alturas. Si ha abusado de su poder desmesurado, es porque se lo ha dejado llegar hasta ese nivel. Porque el poder del poderoso se deriva, tanto de sus méritos excepcionales, cuanto de la complicidad y complacencia de sus subalternos. Se le empodera aceptando su liderazgo, siguiendo sus directrices, trabajando para él o dependiendo de él. De lo contrario, aquel terminaría arando en el desierto como colono ilusionado. Por tanto, se puede contener su expansión y es posible desactivar su poder, si se actúa concertadamente con ese propósito.

Con todo, estas medidas de contención resultarían insuficientes si la estrategia no contase con algunas iniciativas complementarias. Pues no basta con ponerle frenos al poder: también hay que oponerle contrapesos, recogiendo la ingeniosa idea de los fundadores de los EE. UU. No se debe satanizar al poderoso, sino que hay que aprender de él; al menos, en cierto modo y medida. Porque no hay razón para que el subalterno evite emular al poderoso, mientras actúe dentro de la ley. Entretanto, buscará el modo de contenerlo en todo lo que pueda acarrearle algún perjuicio.

Para lograrlo, deberá descubrir sus técnicas, descifrar sus artimañas, curtirse en la lucha, perder la inocencia, asumir riesgos y, sobre todo, aliarse con seres afines. Frente al poderoso, nada mejor que aplicar la reciprocidad en su versión proactiva (do ut des), en tanto se pueda, y la reciprocidad en su versión preventiva (toma y daca), en tanto corresponda. En otros términos, tratar a los demás así como se querría ser tratado por ellos, cuando sea posible, y tratar a los demás así como se es tratado por ellos, cuando sea necesario, o también: mientras no haya alternativa, recelar del desconfiado, enredar al embustero, engañar al impostor, defraudar al traidor, desairar al ventajoso; callar ante el circunspecto, no cooperar con el egoísta, y no compadecer al despiadado. En todo lo demás, proceder igual, dado que, cuando se hace lo contrario, alguien sacará provecho sin brindar nada a cambio. 
La cuestión es la siguiente: no hay razón para ser noble con el canalla, ni para ofrecer la otra mejilla. Quien lo hace quizás pueda superarlo, en términos axiológicos (de valor), pero se le subordina, en términos cratológicos (de poder), quedando a su merced. No olvidar que el valor más supremo del poderoso, es el principio de supervivencia. En su caso, este principio preside todos los demás, sobrepasando incluso los principios morales, en cuyo caso, termina convertido en la fuente del mal, por excelencia.

De allí que el subalterno jamás habrá de ser complaciente con el poderoso, pues ya sabe lo que puede esperar de él. Sabe que el poderoso siempre intentará obtener una ventaja de los demás, para mantenerse encaramado sobre los hombros ajenos. Siempre sabrá arreglárselas para que otros trabajen para él. Usará y abusará de ellos. Los despojará de sus pertenencias legalmente, si es posible, o ilegalmente, si es necesario. Los subyugará, si se le permite hacerlo y los pisoteará si tiene la oportunidad. Por lo tanto, deberá cuidarse él, porque siempre tratará de presentarse como necesario y, más que eso, como indispensable para los demás. Infortunadamente, habrá muchos incautos dispuestos a creer a pie juntillas lo que dice. Llegarán no solo a sentir gratitud hacia él, sino que, en los casos más extremos, sentirán algo más fuerte, más íntimo, más fatal, algo muy cercano al éxtasis religioso: sentirán veneración por él y cuando el subalterno llega a este punto, está perdido.

Admitámoslo: no es fácil poner en marcha una ética del empoderamiento. La dificultad radica en que su viabilidad no depende exclusivamente de la buena voluntad de sus promotores, ni de la buena disposición de sus destinatarios, esto es, la masa de los desposeídos. En realidad, estos últimos se encuentran atrapados en una especie de callejón sin salida, en un círculo vicioso o, peor aún, en un intrincado laberinto, esperando a ser devorados por la insaciable bestia en cualquier recodo del camino. Muchos ni se enteran de la desdichada situación en que se encuentran o, en todo caso, no saben cómo salir de ella o ni siquiera se les ocurre pensar en el asunto. Ello se debe a que, por desgracia, han sido adoctrinados, generación tras generación, por el discurso patriótico-religioso imperante para libar, ensimismados, el agridulce néctar otorgado por las mieles de la resignación y el sometimiento. En consecuencia, estas masas malogradas no pueden redimirse a sí mismas, están alienadas. Necesitan ayuda para salir del foso y, forzosamente, esta ayuda debe proceder del exterior. Pero no es piedad ni caridad lo que requieren, sino compasión, pues, como señala Mèlich, no se trata de ponerse en el lugar del otro - actitud de quien pretende ser condescendientesino de hacerse al lado del otro, ese infortunado a quien se reconoce como un igual (2010, pp. 87ss. y p. 252). Se trata, ante todo, de ofrecerles una ética del empoderamiento, cuya divisa no podría expresarse mejor que en las palabras del conocido proverbio chino que reza así: regala un pescado a un hombre y le darás alimento para un día, enséñale a pescar y lo alimentarás para el resto de su vida. 


\section{Referencias}

Alain (2016). El ciudadano contra los poderes. Madrid: Tecnos.

Alcaldía de Medellín. Campaña Portate Bien. Porque en Medellín se toma conciencia sobre los comportamientos que alteran la convivencia ciudadana. Recuperado de https://www.medellin.gov.co/irj/portal/medellin?NavigationTa rget=navurl://3c3092487d6a9ab5522a091106130533

Arendt, H. (2002). La vida del espíritu. Buenos Aires: Paidós.

Bauman, Z. (2011). Modernidad y holocausto. Madrid: Sequitur.

De Greiff, L. (2013). Antología. Bogotá: Fondo de Cultura Económica.

Federico II de Prusia (1995). Antimaquiavelo o Refutación del Príncipe de Maquiavelo. (Editado en 1740 por Voltaire). Bilbao: Centro de Estudios Constitucionales.

Ferrero, G. (1991). El poder. Los genios invisibles de la ciudad. Madrid: Tecnos.

García, I. (2013). El Corán. Bogotá: Versión Interactiva.

Kant, I. (1972). Lo bello y lo sublime. Madrid: Espasa-Calpe.

Kant, I. (1977). Crítica del juicio. Madrid: Espasa-Calpe.

Los prisioneros. El baile de los que sobran. Recuperado de https://www.youtube. com/watch?v=uPJrZFBiy-A.

Maquiavelo, N. (2011). Maquiavelo. Barcelona: Gredos.

Mèlich, J. (2010). Ética de la compasión. Barcelona: Herder.

Nietzsche, F. (1976). Ecce homo. Madrid: Alianza.

Nietzsche, F. (2008). Fragmentos póstumos IV. Madrid. Tecnos.

Nietzsche, F. (2010a). Nietzsche I. Madrid: Gredos.

Nietzsche, F. (2010b). Fragmentos póstumos III. Madrid. Tecnos.

Nietzsche, F. (2011). Nietzsche II. Madrid: Gredos. 
Pascal, B. (1984). Pensamientos. Madrid: Sarpe.

Reina-Valera (1960). La Santa Biblia. Recuperado de www.bibles.org.uk

Safranski, R. (2001). Nietzsche. Biografía de su pensamiento. Barcelona: Tusquets.

Santiago, T. (2009). "El dilema de la guerra". En M. Barbosa y Z. Yébenes (eds.), Silencios, discursos y miradas sobre la violencia. Barcelona: Anthropos.

Serrat J. M. Fiesta. Recuperado de https://www.youtube.com/watch?v=JW7YAdxLIQ

Villares, R. y Bahamonde, A. (2001). El mundo contemporáneo. Siglos XIX y XX. Madrid: Taurus.

Watson, P. (2002). Historia intelectual del siglo XX. Barcelona: Crítica. 